\title{
Analisis Kualitas Butir Soal Buatan Guru Mata Pelajaran Matematika Kelas VIII SMP Negeri Satap Matabulu Kabupaten Bolaang Mongondow Timur
}

\author{
Metriks Balau $^{1 *}$, Anekke Pesik ${ }^{1}$, I Wayan Damai ${ }^{1}$
}

1Pendidikan Matematika, Fakultas Matematika dan Ilmu Pengetahuan Alam, Universitas Negeri Manado

*e-mail: metriksbalau07@gmail.com

\begin{abstract}
ABSTRAK
Penelitian dilakukan untuk mengevaluasi apakah butir soal memiliki kualitas yang baik dengan mengetahui kevalidan soal, kehandalan soal, indeks kesukaran soal, daya pembeda soal, dan efektifitas pengecoh soal. Penelitian ini menggunakan pendekatan kuantitatif dengan jenis penelitian deskriptif. Teknik pengumpulan data yang digunakan adalah wawancara dan dokumentasi. Penelitian ini dilaksanakan di SMP Negeri Satap Matabulu, Kabupaten Bolaang Mongondow Timur dengan subjek penelitian siswa kelas VIII yang berjumlah 24 siswa. Hasil penelitian ini menunjukkan bahwa kualitas soal memiliki kualitas kurang baik karena belum sesuai dengan soal standar, sehingga perlu adanya perbaikan. Hasil analisis menunjukkan kualitas soal yaitu 11 tes valid dan 19 tes tidak valid. Termasuk reliabilitas soal yang sangat tinggi. efektivitas pengecoh 20 berfungsi dan 10 tidak berfungsi. Untuk Indeks kesukaran soal yaitu 12 mudah, 18 sedang dan tidak ada yang sukar. Daya pembeda 22 jelek, 3 cukup, dan 5 soal baik.
\end{abstract}

Kata kunci: Tes Buatan Guru, Valid, Reliabel

\begin{abstract}
The research was conducted to evaluate whether the items were of good quality by knowing the validity of the questions, the reliability of the questions, the difficulty index, the distinguishing power of the questions, and the effectiveness of the questions. The data collection techniques used were interviews and documentation. This research was conducted at SMP Negeri Satap Matabulu, Kabupaten Bolaang Mongondow Timur district with the research subjects of grade students totaling 24 students. The results of this study indicate that the quality of the questions is of poor quality because they are not following the standards, so it is necessary to improve. The results of the analysis showed that the quality of the questions was 11 valid tests and invalid tests. Including the reliability of very high questions. The effectiveness of the trickster 20 works and 10 doesn't work. For the item difficulty index, it was 12 young, 18 moderate and none were difficult. The distinguishing power of 22 is bad, 3 is enough and 5 is good.
\end{abstract}

Keywords: Quality of Test, Validity, Reliability

\section{PENDAHULUAN}

Pendidikan sangat penting bagi semua orang. Pendidikan adalah proses pembelajaran untuk menyiapkan siswa melalui kegiatan bimbingan dan latihan sehingga siswa memperoleh pengetahuan, keterampilan, kecerdasan dan memiliki karakter yang baik, baik untuk diri sendiri maupun masyarakat. Hasil belajar merupakan kemampuan yang diperoleh siswa setelah mengikuti kegiatan belajar. Dengan hasil belajar guru dapat melihat kemampuan atau pemahaman siswa tentang materi yang telah diajarkan. Tugas guru adalah mendidik siswa dan guru juga sebagai sumber belajar tidak hanya dituntut untuk mengetahui materi ajar dan bagaimana metode mengajarnya saja, tetapi guru juga harus menguasai teknik evaluasi dengan benar sehingga guru dapat melakukan penilaian yang tepat.

Evaluasi merupakan kegiatan penting dalam pembelajaran untuk memahami kemampuan atau hasil belajar siswa. Evaluasi dilakukan untuk memperhatikan kesalahan yang ada dimasa lalu agar kedepannya menjadi lebih baik lagi demi keberhasilan suatu program yang dilakukan. Salah satu kegiatan guru melakukan evalusai adalah dengan memberikan tes kepada siswa. Tes merupakan suatu cara mengevaluasi dalam bentuk rangkaian tugas untuk mengukur seberapa besar pemahaman siswa pada materi yang telah diajarkan guru. 
Tes sumatif adalah tes yang dilakukan setelah menyelesaikan serangkaian rencana pembelajaran contohnya adalah Ujian akhir. Ujian akhir adalah suatu alat yang dipakai sekolah dalam mengevaluasi hasil belajar siswa. Untuk mengetahui kualitas soal tes, perlu dilakukan tes dengan cara menganalisis soal-soal. Tujuan dari menganalisis soal yaitu dengan memeriksa dan menelaah untuk mendapatkan yang berkualitas, sehingga dapat meningkatkan kualitas pengujian dengan merevisi serta menghilangkan soal yang baik.

Menurut penelitian Eyrene M. (2020), menyatakan bahwa semua soal yang dilakukan oleh guru matematika kelas X SMA Negeri 1 Airmadidi tahun pelajaran 2019/2020, ada soal yang diajukan guru termasuk tidak valid dan tingkat kesulitan soal terlalu tinggi. Dalam penelitian Astuti (2020) hasil analisis soal matematika di SD Negeri 005 Binuang tahun ajaran 2018/2019, dari 30 soal menunjukkan kualitas soal yaitu 26 tes valid dan 4 tes tidak valid, reliabilitas soal yang sangat tinggi yaitu 0,823. Indeks kesukaran 15 mudah, 13 sedang, 2 sukar. Daya pembeda 2 jelek, 7 cukup, 19 baik, 2 baik sekali. Efektivitas pengecoh 2 yang berfungsi sangat baik, 3 berfungsi baik, 7 cukup, 9 kurang baik, dan 9 jelek. Dalam penelitian Tilaar, Anetha L.F. (2019) menyatakan bahwa hasil penelitian di kelas VIII SMPN Pineleng tahun ajaran 2018/2019 dengan validitas soal melampaui $50 \%$ dari jumlah soal yakni terdapat 21 soal yang valid. reliabilitas tes termasuk kategori cukup dengan indeks reliabilitas senilai 0,5 . Daya pembeda soal sudah baik karena terdapat 3 soal dengan daya pembeda yang cukup dan 6 butir soal yang memiliki daya pembeda yang baik. Hasil penelitian tersebut memberi gambaran bagi kita bahwa masih terdapat butir-butir soal buatan guru yang tidak berkualitas. Hal ini selaras dengan permasalahan yang terjadi di SMP Negeri Satap Matabulu.

Menurut hasil wawancara dari guru matematika di SMP Negeri Satap Matabulu bahwa proses evaluasi belum memperhatikan penilaian terhadap kualitas alat yang digunakan berupa soal pilihan ganda. Sehingga kualitas soal tersebut belum diketahui apakah itu memenuhi persyaratan sebagai alat ukur. Keterbatasan waktu dan tenaga menjadi faktor tidak terlaksananya proses analisis tersebut. Hasil ujian akhir semester ganjil siswa kelas VIII didapati bahwa hasil belajar siswa rendah karena banyak siswa mengikuti ujian tersebut belum mencapai KKM yang sudah ditentukan. Untuk menghasilkan soal yang bermutu diperlukan analisis untuk mengetahui kualitas soal sebelum diuji cobakan kepada siswa. Kualitas soal sangat mempengaruhi hasil belajar siswa untuk itu analisis butir soal sangat diperlukan agar mengetahui masalah yang terkandung pada soal tersebut. Tujuan dari penelitian ini adalah untuk mengetahui kualitas tes soal buatan guru pada ujian semester genap di kelas VIII SMP Negeri Satap Matabulu Kabupaten Bolaang Mongondow Timur tahun ajaran 2019/2020, ditinjau dari validitas, reliabilitas, efektivitas pengecoh, tingkat kesukaran dan daya pembeda.

\section{METODE}

Metode penelitian yang digunakan dalam analisis tes buatan guru matematika adalah metode deskriptif, yaitu dengan menganalisis soal-soal yang diajukan guru terutama validitas, reliabilitas, pengecoh soal, tingkat kesukaran, dan kemampuan daya pembeda. Berikut adalah rumus yang digunakan untuk mencari validitas, reliabilitas, efektivitas Pengecoh, tingkat kesukaran dan daya pembeda.

Analisis untuk setiap item menggunakan rumus:

$$
-\mathrm{r}_{\mathrm{pbi}}=\frac{M_{p-} M_{t}}{S D_{t}} \sqrt{\frac{p}{q}}
$$

(Anas Sudijono, 2015)

Keterangan:

$r_{p b i}=$ Koefisien korelasi poin biserial

$\mathrm{M}_{\mathrm{P}}$ = Skor rata-rata hitung yang dimiliki oleh testee, yang untuk butir item yang bersangkutan telah dijawab dengan benar

$\mathrm{M}_{\mathrm{t}} \quad=$ Skor rata-rata dari skor total

$\mathrm{SD} / \mathrm{t}=$ Deviasi standar dari skor total

$\mathrm{p} \quad=$ Proporsi testee yang menjawab benar

$\mathrm{q}=$ Proporsi testee yang menjawab salah 
Analisis reliabilitas dilakukan dengan cara mengkorelasikan kelompok-kelompok pertanyaan (soal) sepadan. Dan prosedurnya dilakukan dengan membagi satu tes menjadi dua bagian yang sama.

Dengan,

$$
\mathrm{r}_{\mathrm{i} X Y}=\frac{N \sum X Y-\left(\sum X\right) \sum Y}{\sqrt{\left[N \sum X^{2}-\left(\sum X\right)^{2}\right]\left[N \sum Y^{2}-\left(\sum Y\right)^{2}\right]}}
$$

$$
\mathrm{r}_{\mathrm{tt}}=\frac{2 r_{0 E}}{1+r_{0 E}}
$$

Keterangan :

(Joesmani, 1988)

$r_{0 E}=$ Korelasi skor kelompok nomor ganjil dan kelompok nomor genap

$N$ = Banyaknya Peserta Tes

$O=$ Odd - ganjil

$E=$ Even - genap

$X=$ Skor kelompok nomor ganjil

$Y=$ Skor kelompok nomor genap

$\mathrm{r}_{\mathrm{tt}}=$ Koefisien Reliabilitas Tes Objektif

Untuk menguji berfungsi tidaknya suatu distraktor dapat dihitung dengan rumus:

Keterangan :

$$
\mathrm{r}_{\mathrm{opsi}}=\frac{N \sum X_{o p s i} y-\left(\sum X_{o p s i}\right) \sum Y}{\sqrt{\left[N \sum X_{o p s i}^{2}-\left(\sum X_{o p s i}\right)^{2}\right]\left[N \sum Y^{2}-\left(\sum Y\right)^{2}\right]}}
$$

$r_{o p s i}=$ Validitas Opsi distraktor pada butir item soal

$\mathrm{N} \quad=$ Banyaknya peserta tes

$X_{\text {opsi }}=$ Skor total peserta tes yang merespon opsi

$\mathrm{Y} \quad=$ Skor total seluruh peserta tes

$\sum X^{2}=$ Jumlah Kuadrat dari Nilai $X_{O p s i}$

$\sum Y^{2}=$ Jumlah Kuadrat dari nilai $Y$

$\left(\sum X\right)^{2}=$ Jumlah nilai $X_{\text {opsi }}$ kemudian dikuadratkan

$\left(\sum Y\right)^{2}=$ Jumlah nilai $Y$ kemudian dikuadratkan

Rumus yang digunakan untuk menghitung indeks kesukaran butir soal untuk bentuk soal objektif sebagai berikut.

$$
P=\frac{B}{J S}
$$

(Suharsimi Arikunto, 2012)

Keterangan :

$P=$ Indeks kesukaran

$B$ = Banyaknya siswa yang menjawab soal itu dengan benar

$J S=$ Jumlah seluruh siswa peserta tes

Daya pembeda soal (soal objektif-pilihan ganda) menurut indeks daya pembeda dapat

dicari dengan menggunakan rumus:

$$
\mathrm{DP}=\frac{2\left(\mathrm{~B}_{\mathrm{A}}-\mathrm{B}_{\mathrm{B}}\right)}{\mathrm{N}}
$$

(Crocker \& Algina, 1986)

Keterangan :

$\mathrm{DP}=$ Indeks daya pembeda soal

$B_{A}=$ Banyaknya peserta tes yang menjawab benar pada kelompok atas

$B_{B}=$ Banyaknya peserta tes yang menjawab benar pada kelompok bawah

$\mathrm{N}=$ Banyaknya peserta tes 


\section{HASIL DAN PEMBAHASAN}

Penelitian dilaksanakan di SMP Negeri Satap Matabulu tahun ajaran 2019/2020. Data yang dianalisis adalah lembar jawaban siswa kelas VIII pada ujian akhir semester ganjil mata pelajaran matematika. Analisis data ujian akhir semester diuraikan pada penjelasan dibawah ini.

\section{Uji Validitas Soal}

Validitas mengacu pada seberapa akurat suatu metode untuk mengukur kualitas soal. Jika penelitian memiliki kualitas tinggi, artinya menghasilkan hasil yang sesuai dengan sifat, karakteristik, dan variasi nyata dalam dunia fisik atau sosial.

Jika soal bersangkutan dinyatakan valid maka $r_{\text {hitung }}>r_{\text {tabel, }}$ sebaliknya juga jika soal bersangkutan dinyatakan tidak valid $r_{\text {hitung }}<r_{\text {tabel. }}$ Pada Tabel 1 diperoleh hasil analisis uji validitas sebagai berikut.

Tabel 1. Interpretasi Analisis Butir Soal Kelas Kelas VIII SMP Negeri Satap Matabulu

\begin{tabular}{lcc}
\hline Interpretasi & Jumlah Soal & Nomor Soal \\
\hline Valid & 11 & $8,9,11,13,14,17,20,23,26,29,30$ \\
\hline Tidak Valid & 19 & $1,2,3,4,5,6,7,10,12,15,16,18,19,21,22,24,25,27,28$ \\
\hline
\end{tabular}

\section{Reliabilitas Soal}

Reliabilitas yaitu keseluruhan suatu ukuran. Alat ukur memiliki keandalan yang tinggi ketika menghasilkan hasil yang sama dalam kondisi yang konsisten. Koefisien reliabilitas instrument ini dihitung menggunakan rumus Spear-Brown. Dimana analisis ini dilakukan dengan membelah dua butir soal yang sama atau membagi pengelompokkan berdasarkan nomor ganjil (odd) dan soal bernomor genap (even). Hasil dan interpretasinya adalah sebagai berikut.

Untuk kelas VIII SMP Negeri Satap Matabulu, koefisien korelasi yang diperoleh dengan menggunakan metode belah dua ganjil dan genap Spearman-Brown adalah $r_{O E}=0,63$ dengan demikian koefisien korelasi tes pilihan ganda $r_{t t}=0,77$. Hal ini menunjukkan bahwa dengan $\mathrm{n}=24$ yang sama pada taraf signifikansi $5 \%$ dengan koefisien reliabiltas $0,77>0,63$. Sehingga ada korelasi signifikan, dan hasil tes belajar dari Kelas VIII SMP Negeri Satap Matabulu dianggap reliabel.

\section{Fungsi Distraktor}

Jika minimal $5 \%$ dari peserta tes memilih distraktor, Jawaban atas distraktor bisa menjalankan fungsinya. Menghitung fungsi distractor dilakukan dengan cara: (1) Menghitung banyaknya testee yang menjawab option (2) Menghitung rumus efektivitas fungsi pengeco.

Interpretasinya yakni jika koefisien validitas pengecoh bernilai positif maka opsi tersebut tidak berfungsi sebagaimana mestinya. Pada Tabel 2 diperoleh hasil analisis distraktor baik Kelas VIII SMP Negeri Satap Matabulu sebagai berikut

Tabel 2. Hasil Analisis Fungsi Distraktor Kelas VIII SMP Negeri Satap Matabulu

\begin{tabular}{ccc}
\hline Nomor Soal & Kunci & Distraktor yang Berfungsi \\
\hline 1 & D & - \\
\hline 2 & C & - \\
\hline 3 & B & - \\
\hline 4 & E & A \\
\hline 5 & D & - \\
\hline 6 & C & B \\
\hline 7 & C & A, B, C \\
\hline 8 & D & A, B, C \\
\hline 9 & D & - \\
\hline 10 & A & A, B, \\
\hline 11 & D & B, C, D
\end{tabular}




\begin{tabular}{ccc}
\hline 13 & B & A, C, D \\
\hline 14 & A & B, C, D \\
\hline 15 & A & - \\
\hline 16 & C & A, B, D \\
\hline 17 & D & A, B, C \\
\hline 18 & B & - \\
\hline 19 & C & A \\
\hline 20 & D & A, C \\
\hline 21 & C & A, B, D \\
\hline 22 & C & A, C, D \\
\hline 23 & B & - \\
\hline 24 & D & B \\
\hline 25 & A & A, B, C \\
\hline 26 & D & - \\
\hline 27 & B & C \\
\hline 28 & E & A, C, D \\
\hline 29 & B & B, C \\
\hline 30 & D &
\end{tabular}

\section{Tingkat Kesukaran}

Kualitas soal tidak mudah atau tidak sulit adalah soal yang baik. Jadi, pengujian ini mempengaruhi apakah siswa memiliki kesanggupan dalam menjawab soal tersebut. Mengukur tingat kesukaran tes rumusnya adalah:

$$
P=\frac{B}{J S}
$$

(Suharsimi Arikunto 2012)

Kriteria indeks kesukaran item yaitu:

$0,00-0,30$ Sukar

$0,31-0,70$ Sedang

$0,71-1,00$ Mudah

Untuk hasil pengukuran tingkat kesukaran dapat dillihat pada Tabel 3 berikut.

Tabel 3. Interpretasi Tingkat Kesukaran Kelas VIII SMP Negeri Satap Matabulu

\begin{tabular}{|c|c|c|}
\hline Interpretasi & Jumlah Soal & Nomor Soal \\
\hline Sukar & - & - \\
\hline Sedang & 18 & $4,5,7,8,9,11,12,14,19,20,22,23,25,26,28,29,30$ \\
\hline Mudah & 12 & $1,2,3,6,10,13,15,16,18,21,24,27$ \\
\hline
\end{tabular}

\section{Daya Beda}

Pengujian daya pembeda sangat penting. Agar kita dapat membedakan tingkat tingkat kemampuan siswa yang mampu dan tidak mampu. Untuk mengukur daya pembeda menggunakan rumus:

$$
\mathrm{D}=\frac{2\left(B_{A-B_{b}}\right)}{N}
$$


Kriteria daya pembeda yang digunakan yaitu:

$0,00-0,20$ Poor

$0,21-0,40$ Satisfactory

$0,41-0,70$ Good

$0,71-1,00$ Excellent

Hasil negatif termasuk sangat jelek.

Pada Tabel 4 diperoleh hasil daya pembeda sebagai berikut.

Tabel 4. Intepretasi Indeks Daya Beda Kelas VIII SMP Negeri Satap Matabulu

\begin{tabular}{lcc}
\hline \multicolumn{1}{c}{ Intepretasi } & Jumlah Soal & \multicolumn{1}{c}{ Nomor Soal } \\
\hline Lemah (Poor) & 22 & $\begin{array}{l}1,2,3,6,7,8,9,10,11,13,14,15,17,18, \\
20,21,23,24,26,27,29,30\end{array}$ \\
\hline Cukup (Satisfactory) & 3 & $5,16,22$ \\
\hline Baik (Good) & 5 & $4,12,19,25,28$ \\
\hline Sangat Baik (Excellent) & - & - \\
\hline
\end{tabular}

\section{KESIMPULAN}

Berdasarkan hasil penelitian maka kesimpulannya soal tes buatan guru di SMP Negeri Satap Matabulu Kabupaten Bolaang Mongondow Timur perlu dianalisis terlebih dahulu sebelum diujikan kepada siswa meskipun guru sudah berpengalaman dalam menyusun soal. Demikian juga seringkali dalam menyusun soal guru belum menyadari bahwa soal yang dibuat masih kurang sempurna. Untuk itu soal berkualitas baik dapat digunakan lagi saat ujian akhir semester berikutnya, kualitas soal jelek harus diperbaiki serta harus diganti.

\section{DAFTAR PUSTAKA}

Anas Sudijono. (2015). Pengantar Evaluasi Pendidikan. Jakarta: PT Raja Grafindo Persada.

Eyrene M. (2020). Analisis Kualitas Butir Soal Buatan Guru Mata Pelajaran Matematika Kelas X SMA Negeri 1 Airmadidi tahun ajaran 2019/2020. Jurnal Sains, Matematika \& Edukasi, 8(2). Diambil dari http: //ejournal.unima.ac/index.php/jsme/index.

Agina, James \& Crocker, Linda (1986). Introduction to Classical and Modern Test Theory. Florida: Holt, Rinehart and Wiston, Inc.

Joesmani. (1998). Pengukuran dan Evaluasi dalam Pengajaran, Cet, I. Jakarta: Dikti.

Suharsimi Arikunto. (2012). Dasar-Dasar Evaluasi Pendidikan: Edisi 2. Jakarta: Bumi Aksara

Astuti. (2020). Analisis Soal Ujian Akhir Semester Genap Mata Pelajaran Matematika Siswa SD Negeri 005 Binuang Ajaran 2017/2018. Jurnal Pendidikan Tambusai, 4(1). Diambil dari https://jptam.org./index.php//jptam/article/view/539.

Tilaar, Anetha L.F. (2019). Analisis Butir Soal Semester Ganjil Mata Pelajaran Matematika siswa SMPN Pineleng tahun ajaran 2018/2019. Jurnal Pengukuran Psikologi dan Pendidikan Indonesia, 8(1). Diambil dari http://dxg.doi.org/10.15408/jpt3i.v8i11.13068 